\title{
Large uterine pyomyoma in a perimenopausal female: A case report and review of 50 reported cases in the literature
}

\author{
NAOYUKI IWAHASHI, YASUSHI MABUCHI, MICHIHISA SHIRO, \\ SHIGETAKA YAGI, SAWAKO MINAMI and KAZUHIKO INO
}

Department of Obstetrics and Gynecology, Wakayama Medical University, Wakayama 641-0012, Japan

Received February 15, 2016; Accepted April 7, 2016

DOI: $10.3892 / \mathrm{mco} .2016 .1005$

\begin{abstract}
Pyomyoma is a rare complication, which withoug antibiotics or surgical intervention, may cause sepsis and mortality. The present study reported a case of large uterine pyomyoma in a perimenopausal female. A 53-year-old multigravida woman was referred to the Department of Obstetrics and Gynecology (Wakayama Medical University, Wakayama, Japan) due to progressive abdominal distension. The patient presented with anemia gravis, severe inflammatory reaction and cachexia. Computed tomography revealed a large unilocular mass, $50 \mathrm{~cm}$ in size, with an irregular surface and thickened wall, occupying the entire abdomen. Following antibiotic medication, the patient underwent a total abdominal hysterectomy and bilateral salpingo-oophorectomy. Intraoperative findings demonstrated a solid tumor arising from the back of the uterine body. A total of 12 liters of purulent, malodorous fluid was drained from the tumor. The resected mass was $50 \mathrm{~cm}$ in size and $13.5 \mathrm{~kg}$ in weight. Cultures of the pus revealed the presence of Streptococcus agalactiae. Pathological findings revealed suppurative leiomyoma with no malignancy. Large pyomyoma is difficult to distinguish from a gynecological malignant tumor types, particularly in perimenopausal women with non-specific clinical presentation. Although pyomyoma is a benign tumor, care must be taken to discriminate these from large abdominal tumors.
\end{abstract}

\section{Introduction}

Pyomyoma (suppurative leiomyoma) is a rare, but life-threatening, condition resulting from infarction and infection of uterine leiomyoma $(1,2)$. Incidence of pyomyoma has decreased due to the development of antibiotics. Since 1945, only 50 pyomyoma cases have been documented in the

Correspondence to: Dr Naoyuki Iwahashi, Department of Obstetrics and Gynecology, Wakayama Medical University, 811-1 Kimiidera, Wakayama 641-0012, Japan

E-mail: naoyuki@wakayama-med.ac.jp

Key words: pyomyoma, gynecological tumor, severe inflammatory reaction, cachexia, perimenopause literature, with a mortality rate of $6 \%(3 / 50)(3-5)$. The most likely cause of mortality was delayed and difficult diagnosis. Although the triad of pyomyoma are sepsis, leiomyoma, and no other source of infection (5), it may present with silent or non-specific symptoms, which results in delayed diagnosis and treatment. Visualization of intratumoral gas formation may be suggestive of pyomyoma, but has not been consistently reported in all cases. Furthermore, large abdominal complex masses are likely to be first suspected as pelvic malignancies if found incidentally in perimenopausal women.

The present study experienced a rare case of large uterine pyomyoma in a perimenopausal woman who presented with anemia gravis, severe inflammatory reaction and cachexia. A total of 50 reported cases of pyomyoma in the literature since 1945 were also studied.

\section{Case report}

A 53-year-old multigravida woman with 7 months of amenorrhea was referred to the Department of Obstetrics and Gynecology (Wakayama Medical University, Wakayama, Japan) due to gradual abdominal distension starting 2 years previously. The patient exhibited muscle weakness and walking difficulty, but no fever, abdominal pain or metrorrhagia. Her abdomen was swollen to the size of a beach ball, with a $126 \mathrm{~cm}$ abdominal circumference and body weight of $84.1 \mathrm{~kg}$. An intrauterine device (IUD) had been inserted following her third birth, and no history of any lower abdominal or pelvic discomfort, leiomyoma, pelvic surgery, or other predisposing factors were known. The present study was unable to determine the uterine cervix with pelvic examination due to its deviation, and was unable to acquire cytopathological findings of the cervix and endometrium. Transvaginal and transabdominal ultrasound examinations revealed a large abdominal mass with heterogeneous echogenicity. Computed tomography $(\mathrm{CT})$ and magnetic resonance imaging (MRI) revealed a large unilocular mass with an irregular surface and thickened wall, occupying the abdominal cavity without gas formation (Fig. 1). Contrast CT revealed an expanded branch of the left internal iliac artery, which was suspected to be the uterine artery, surrounding the mass (Fig. 1B). Hemoglobin levels were $5.7 \mathrm{~g} / \mathrm{dl}$, white blood cell count was $57,300 / \mu 1$ and C-reactive protein was elevated to $20.24 \mathrm{mg} / \mathrm{dl}$. Cancer antigen (CA)125 was also elevated to $200 \mathrm{U} / \mathrm{ml}$. Blood and 

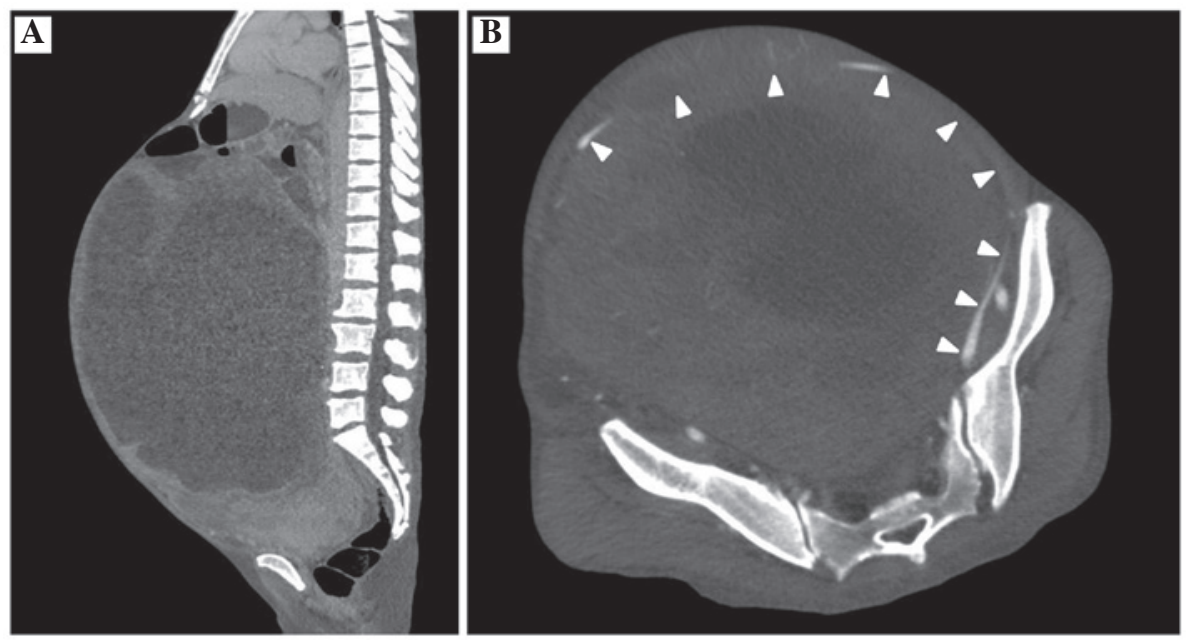

Figure 1. CT findings of pyomyoma. (A) Non-contrast CT and (B) contrast CT revealed the left uterine artery (arrow head) running over a large mass. CT, computed tomography.
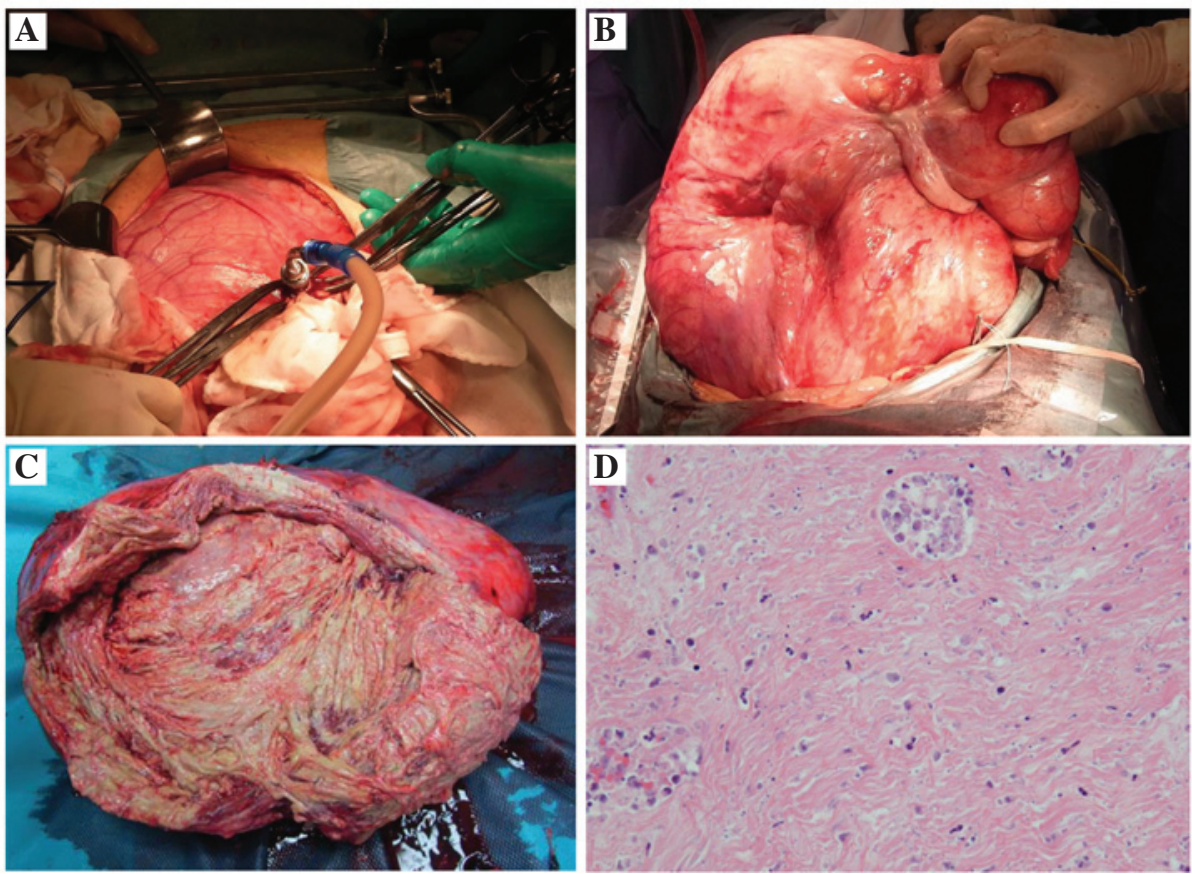

Figure 2. Macroscopic and microscopic findings of pyomyoma. (A) Open drainage from the mass. (B and C) Macroscopic finding of the mass. (D) Microscopic findings following staining with hematoxylin and eosin (magnification, x200).

vaginal cultures were negative. Possible diagnoses of the large abdominal mass included gynecologic tumor types (benign or malignant ovarian tumor, uterine sarcoma or pyometra) and gastrointestinal stromal tumor or mucocele of the appendix. Gastroscopy revealed no specific findings and colonoscopy revealed difficulty of insertion above the sigmoid colon due to pressure from the mass. Due to the finding of the uterine artery by contrast CT, the origin of the mass was suspected to be the uterus. Following antibiotic medication and blood transfusion, the patient underwent a total abdominal hysterectomy and bilateral salpingo-oophorectomy. Ureteral stents were indwelled in each side pre-operatively. Intraoperative findings demonstrated a solid tumor arising from the back of the uterine body with normal bilateral adnexa. Prior to removal, 12.4 liters of purulent, malodorous fluid was drained from the tumor (Fig. 2A and B). The resected mass was $50 \times 37 \times 20 \mathrm{~cm}$ in size and $13.5 \mathrm{~kg}$ in weight. The surrounding myometrium appeared normal and measured $3 \mathrm{~cm}$ in thickness, and the cut surface of the mass was purple-yellowish (Fig. 2C). Cultures of the pus in the tumor revealed the presence of Streptococcus agalactiae. An IUD was identified near the cervix, however culture was negative. The pathological diagnosis was leiomyoma with marked necrosis and chronic inflammation, with no evidence of malignancy (Fig. 2D). Following resection of the tumor, the patient's weight decreased to $55 \mathrm{~kg}$. The post-operative course was uneventful and the patient was discharged from the hospital on post-operative day 14. At 4 months follow-up, the patient's weight had increased to $62 \mathrm{~kg}$ due to a good appetite. 
Table I. Previously reported cases of pyomyoma without pregnancy, since 1945.

\begin{tabular}{|c|c|c|c|c|c|c|}
\hline Author, year & Age & Key points & Laboratory data & Size & Treatment $^{\mathrm{a}}$ & Refs. \\
\hline Miller et al, 1945 & 51 & STM & $\mathrm{WBC} 38,700 / \mu 1$ & $35 \times 25 \mathrm{~cm}$ & $\begin{array}{l}\text { Subtotal } \\
\text { hysterectomy + } \\
\text { BSO }\end{array}$ & (3) \\
\hline Kaufmann et al, 1974 & 58 & STM, HT, DM & $\begin{array}{l}\mathrm{WBC} 28,800 / \mu 1, \\
\mathrm{Hb} 7.3 \mathrm{~g} / \mathrm{dl}\end{array}$ & ns & No treatment & (4) \\
\hline Greenspoon et al, 1990 & 49 & STM & $\begin{array}{l}\mathrm{WBC} 21,200 / \mu 1, \\
\mathrm{Hb} 7.4 \mathrm{~g} / \mathrm{dl}\end{array}$ & $\begin{array}{l}11.5 \times 9 \times 11 \mathrm{~cm}, \\
2.5 \mathrm{~kg}\end{array}$ & No treatment & (5) \\
\hline Chen et al, 2014 & 67 & Gas production & $\begin{array}{l}\mathrm{WBC} 12,300 / \mu 1, \\
\mathrm{CA} 12529.98 \mathrm{U} / \mathrm{ml}\end{array}$ & $25 \times 20 \times 15 \mathrm{~cm}$ & $\mathrm{TAH}+\mathrm{BSO}$ & (6) \\
\hline Manchana et al, 2007 & 42 & IUD & $\begin{array}{l}\text { WBC } 29,380 / \mu 1, \\
\mathrm{Hb} 8.7 \mathrm{~g} / \mathrm{dl}, \\
\text { CA125 } 65.2 \mathrm{U} / \mathrm{ml}\end{array}$ & $15 \times 15 \mathrm{~cm}$ & $\mathrm{TAH}+\mathrm{BSO}$ & (8) \\
\hline Kitamura et al, 2005 & ns & $\begin{array}{l}\text { UAE, gas } \\
\text { production }\end{array}$ & ns & ns & TAH & (9) \\
\hline Abulafia et al, 2010 & 48 & $\begin{array}{l}\text { UAE, gas } \\
\text { production }\end{array}$ & $\begin{array}{l}\mathrm{WBC} 22,600 / \mu 1, \\
\mathrm{Hb} 8.1 \mathrm{~g} / \mathrm{dl}\end{array}$ & $11 \times 10 \times 6 \mathrm{~cm}$ & TAH & $(10)$ \\
\hline Shukla et al, 2012 & 65 & $\begin{array}{l}\text { UAE, gas } \\
\text { production }\end{array}$ & WBC $7,900 / \mu 1$ & $12 \times 10 \mathrm{~cm}$ & TAH + BSO & $(11)$ \\
\hline Pinto et al, 2012 & 36 & UAE & $\begin{array}{l}\text { WBC normal, } \\
\mathrm{Hb} 9.5 \mathrm{~g} / \mathrm{dl}\end{array}$ & $6.8 \times 5.6 \times 5.5 \mathrm{~cm}$ & $\begin{array}{l}\text { Laparoscopic } \\
\text { drainage }\end{array}$ & $(12)$ \\
\hline Rosen et al, 2013 & 47 & $\begin{array}{l}\text { UAE, gas } \\
\text { production }\end{array}$ & $\mathrm{WBC} 15,900 / \mu 1$ & $\mathrm{~ns}$ & $\begin{array}{l}\text { Supracervical } \\
\text { hysterectomy + RSO }\end{array}$ & (13) \\
\hline Weiss et al, 1976 & 59 & $\mathrm{DM}$ & ns & $15 \mathrm{~cm}$ & $\mathrm{TAH}+\mathrm{BSO}$ & $(14)$ \\
\hline Genta et al, 2001 & 60 & DM, DVT & $\begin{array}{l}\text { WBC } 14,100 / \mu 1, \\
\mathrm{Hb} 7.7 \mathrm{~g} / \mathrm{dl}, \\
\text { CA125 } 109.7 \mathrm{U} / \mathrm{ml}\end{array}$ & $25 \times 20 \mathrm{~cm}$ & $\begin{array}{l}\text { TAH + BSO + } \\
\text { omentectomy }\end{array}$ & $(15)$ \\
\hline Fletcher et al, 2009 & 44 & $\mathrm{DM}$ & $\begin{array}{l}\text { WBC } 22,500 / \mu 1, \\
\mathrm{Hb} 7.8 \mathrm{~g} / \mathrm{dl}, \\
\text { CA125 } 17.5 \mathrm{U} / \mathrm{ml}\end{array}$ & $15.5 \times 16 \times 9 \mathrm{~cm}$ & $\mathrm{TAH}+\mathrm{BSO}$ & $(16)$ \\
\hline Ono et al, 2014 & 69 & $\mathrm{DM}$ & $\begin{array}{l}\text { WBC } 10,710 / \mu 1 \text {, } \\
\text { CRP } 2.71 \mathrm{mg} / \mathrm{dl}, \\
\mathrm{Hb} 7.6 \mathrm{~g} / \mathrm{dl}\end{array}$ & ns & TAH & $(17)$ \\
\hline Goyal et al, 2015 & 42 & $\mathrm{DM}$ & $\begin{array}{l}\text { WBC } 10,200 / \mu 1, \\
\mathrm{Hb} 9.5 \mathrm{~g} / \mathrm{dl}\end{array}$ & $6 \mathrm{~cm}$ & $\begin{array}{l}\text { Subtotal } \\
\text { hysterectomy + }\end{array}$ & $(18)$ \\
\hline Lee et al, 2010 & 46 & FDG-PET & $\begin{array}{l}\text { WBC } 10,100 / \mu 1, \\
\mathrm{Hb} 8.8 \mathrm{~g} / \mathrm{dl}, \\
\text { CA125 } 59.2 \mathrm{U} / \mathrm{ml}\end{array}$ & $\begin{array}{l}38 \times 30 \times 10 \mathrm{~cm}, \\
3 \mathrm{~kg}\end{array}$ & $\mathrm{LSO}+\mathrm{TAH}$ & $(22)$ \\
\hline Bedrosin et al, 1956 & 50 & N/A & $\begin{array}{l}\mathrm{WBC} 12,800 / \mu \mathrm{l}, \\
\mathrm{Hb} 11.0 \mathrm{~g} / \mathrm{dl}\end{array}$ & $7 \mathrm{~cm}$ & $\mathrm{TAH}+\mathrm{BSO}$ & $(23)$ \\
\hline Fuller et al, 1985 & 68 & N/A & WBC $24,000 / \mu 1$ & $10 \mathrm{~cm}$ & $\mathrm{TAH}+\mathrm{BSO}$ & $(24)$ \\
\hline Yang and Wang, 1999 & 46 & N/A & $\begin{array}{l}\mathrm{WBC} 45,400 / \mu \mathrm{l}, \\
\mathrm{Hb} 7.0 \mathrm{~g} / \mathrm{dl}\end{array}$ & $13 \times 12 \mathrm{~cm}$ & $\mathrm{TAH}+\mathrm{BSO}$ & $(25)$ \\
\hline Gupta et al, 1999 & 60 & N/A & WBC $14,000 / \mu 1$ & $\begin{array}{l}30 \times 25 \mathrm{~cm}, \\
4.3 \mathrm{~kg}\end{array}$ & $\mathrm{TAH}+\mathrm{BSO}$ & $(26)$ \\
\hline Sah et al, 2005 & 64 & N/A & $\begin{array}{l}\mathrm{WBC} 15,000 / \mu 1, \\
\mathrm{Hb} 8.0 \mathrm{~g} / \mathrm{dl}\end{array}$ & $\begin{array}{l}22 \times 23 \times 10 \mathrm{~cm}, \\
3.5 \mathrm{~kg}\end{array}$ & $\mathrm{TAH}+\mathrm{BSO}$ & $(27)$ \\
\hline Yeat et al, 2005 & 53 & N/A & $\begin{array}{l}\mathrm{WBC} 52,600 / \mu \mathrm{l}, \\
\mathrm{CRP} 42.4 \mathrm{mg} / \mathrm{dl}, \\
\mathrm{Hb} 8.6 \mathrm{~g} / \mathrm{dl}\end{array}$ & $\begin{array}{l}12 \times 12 \times 10 \mathrm{~cm}, \\
1,020 \mathrm{~g}\end{array}$ & $\mathrm{TAH}+\mathrm{BSO}$ & $(28)$ \\
\hline
\end{tabular}


Table I. Continued.

\begin{tabular}{|c|c|c|c|c|c|c|}
\hline Author, year & Age & Key points & Laboratory data & Size & Treatment $^{\mathrm{a}}$ & Refs. \\
\hline Patwardhan and Bulmer, 2007 & 38 & N/A & $\begin{array}{l}\text { WBC } 18,500 / \mu l \text {, } \\
\text { CRP } 22.5 \mathrm{mg} / \mathrm{dl}\end{array}$ & ns & Myomectomy & (29) \\
\hline Chen et al, 2010 & 46 & N/A & $\begin{array}{l}\text { WBC } 13,000 / \mu 1 \text {, } \\
\mathrm{Hb} 7.9 \mathrm{~g} / \mathrm{dl}\end{array}$ & $14.3 \times 12 \times 8 \mathrm{~cm}$ & TAH & $(30)$ \\
\hline Kuriyama et al, 2010 & 51 & N/A & $\begin{array}{l}\text { WBC } 15,900 / \mu 1 \text {, } \\
\text { CRP } 13.1 \mathrm{mg} / \mathrm{dl}\end{array}$ & ns & TAH & $(31)$ \\
\hline Zangeneh et al, 2010 & 47 & N/A & $\begin{array}{l}\text { WBC normal, } \\
\mathrm{Hb} 10.3 \mathrm{~g} / \mathrm{dl}\end{array}$ & $3 \times 5 \mathrm{~cm}$ & $\mathrm{TAH}+\mathrm{BSO}$ & $(32)$ \\
\hline Liu and Chen, 2011 & 42 & N/A & WBC $42,880 / \mu 1$ & $9.0 \times 8.0 \times 6.5 \mathrm{~cm}$ & Open drainage & (33) \\
\hline Present report & 53 & IUD & $\begin{array}{l}\text { WBC } 57,300 / \mu 1, \\
\text { CRP } 20.24 \mathrm{mg} / \mathrm{dl}, \\
\mathrm{Hb} 5.7 \mathrm{~g} / \mathrm{dl}, \\
\text { CA125 } 200.2 \mathrm{U} / \mathrm{ml}\end{array}$ & $\begin{array}{l}50 \times 37 \times 20 \mathrm{~cm}, \\
13.5 \mathrm{~kg}\end{array}$ & $\mathrm{TAH}+\mathrm{BSO}$ & - \\
\hline
\end{tabular}

${ }^{\mathrm{a} T r e a t m e n t ~ n o t ~ i n c l u d i n g ~ a n y ~ a n t i b i o t i c s . ~ n s, ~ n o t ~ s p e c i f i e d ; ~ T A H, ~ t o t a l ~ a b d o m i n a l ~ h y s t e r e c t o m y ; ~ B S O, ~ b i l a t e r a l ~ s a l p i n g o-o o p h o r e c t o m y ; ~ R S O, ~}$ right salpingo-oophorectomy; CS, cesarean section; IUD, intrauterine device; DM, diabetes mellitus; UAE, uterine artery embolization; STM, succumbed to mortality; WBC, white blood cell count; Hb, hemoglobin; CA, cancer antigen; CRP, C-reactive protein; N/A, not applicable; HT, hypertension; DVT, deep vein thrombosis; FEG-PED, fluorodeoxyglucose-positron emission tomography; LSO, left salpingo-oophorectomy.

\section{Discussion}

Pyomyoma occurs in both post-and pre-menopausal women, however, the risk of suppurative myoma is increased by pregnancy $(1,2)$. For post-menopausal patients, systemic vascular changes have been suggested to be the likely underlying cause of pyomyoma (6). Necrosis of the leiomyoma caused by vascular flow insufficiency in the uterus following menopause is also a possible cause. A history of uterine leiomyoma, pregnancy, abortion, menopause, uterine artery embolization (UAE), IUD, vascular insufficiency (diabetes, hypertension and atherosclerosis) and systemic disease or infection may be predisposing factors for pyomyoma; however, definitive diagnoses remain difficult. Although rapid clinical diagnosis for pyomyoma is often difficult due to its low incidence and the requirement to rule out the possibility of malignancy, mortality has decreased due to the improvement in surgical treatments, including myomectomy and hysterectomy, and broad-spectrum antibiotics.

A MEDLINE search since 1945 revealed only 50 reported cases of pyomyoma: 27 were non-pregnant woman (mean age, 51.8 years; range, 36-69-years-old; Table I) (3-29) and 23 cases were associated with pregnancy or abortion (mean age, 33.6 years; range, 28-44-years-old). The mean pyomyoma size in non-pregnancy and pregnancy-associated cases were $16.2 \mathrm{~cm}(3-38 \mathrm{~cm})$ and $13.5 \mathrm{~cm}(5-58 \mathrm{~cm})$, respectively. Non-pregnancy pyomyoma tended to be larger compared with pregnancy-associated pyomyoma, and the present case was the largest among all reported cases of non-pregnancy-associated pyomyoma. Severe anemia gravis and inflammatory reaction were described in numerous pyomyoma cases, including the present study. The presentation and complications of pyomyoma vary. It has been shown that $2 / 50$ cases had a history of IUD usage $(7,30), 5 / 50$ cases had UAE (8-12), $6 / 50$ cases had vascular insufficiency $(4,13-17)$ and $8 / 50$ cases demonstrated gas production $(6,8-10,12,31-33)$. Notably, gas production was observed in 4/5 UAE cases $(8-10,12)$. Although pyomyoma arises spontaneously, post-partum, post-instrumentation or post-surgery have been reported in the literature, only two cases include a IUD, and only one case has been previously reported in a non-pregnant woman (7). Knowledge of IUD history may be helpful in the diagnosis of pyomyoma.

Pyomyoma was often associated with polymicrobial infection. Among the 50 reported cases, infection by Staphylococcus species was reported in 8 cases, Streptococcus species in 7 cases, Escherichia coli in 6 cases, Enterococcus faecalis in 5 cases, Clostridium species in 3 cases, Proteus species in 2 cases and Candida species in 2 cases. In the present case, Streptococcus agalactiae was cultured from the pus and tumor, however, not from the blood and vagina, suggesting the infection existed focally within the tumor. Therefore, conservative management with pre-operative broad-spectrum antibiotics and appropriate surgery was performed successfully. For surgical treatment, hysterectomy was performed in 32 cases, myomectomy in 10 cases and drainage in 6 cases.

Diagnosis of large pyomyoma is difficult since surgery is required for a definitive diagnosis. A malignant tumor, in particular ovarian cancer, was initially suspected due to the findings of a large abdominal mass with signs of necrosis in a cachexic perimenopausal woman with an elevated CA125 level. In a previous report, imaging analysis was shown to identify only non-specific results (6). MRI and positron emission tomography did not improve the specificity of pyomyoma diagnosis. Although intratumoral gas formation is markedly suggestive of pyomyoma on ultrasound and CT imaging, gas formation is not consistently observed, as with the present case. In the present case, contrast CT contributed 
to the diagnosis of pyomyoma due to the identification of the uterine artery location.

CA125 has been observed to be increased in other gynecologic and non-gynecologic malignancies, as well as in a variety of benign disorders, including leiomyoma. Among the previously reported cases of pyomyoma, 5 cases reported CA125 levels $(6,7,14,15,18)$, with a mean level of $56.3 \mathrm{U} / \mathrm{ml}(29.98-109.7 \mathrm{U} / \mathrm{ml})$. CA125 was measured only in non-pregnancy-associated cases, possibly due to suspicion of gynecological malignancy based on the age of the patient and size of tumor. Furthermore, in pregnancy-associated cases, diagnosis of myoma was likely during pre-natal examination prior to the onset of the symptom, which may have contributed to the identification of the tumor origin. In the present case, CA125 level was the highest compared with the previously reported cases.

To the best of our knowledge, this is the third IUD-associated case of pyomyoma, with the largest tumor size and highest CA125 level compared with previously reported non-pregnancy cases. A large pyomyoma is difficult to distinguish from a gynecological malignant tumor, particularly in perimenopausal, cachectic women with non-specific clinical presentation and without a history of leiomyoma. A history of IUD usage and contrast CT may be helpful in the diagnosis of pyomyoma. Gynecologists and general surgeons must be aware of the possibility of pyomyoma when presented with a large abdominal tumor, and in certain cases, surgery in combination with broad spectrum antibiotics may result in a good outcome.

\section{References}

1. Mason TC, Adair J and Lee YC: Postpartum pyomyoma. J Natl Med Assoc 97: 826-828, 2005.

2. Kobayashi F, Kondoh E, Hamanishi J, Kawamura Y, Tatsumi K and Konishi I: Pyomayoma during pregnancy: A case report and review of the literature. J Obstet Gynaecol Res 39: 383-389, 2012

3. Miller I: Suppurating fibromyomas. Report of a case with a review of the literature. Am J Obstet Gynecol 50: 522-526, 1945

4. Kaufmann BN, Cooper VM and Cookson P: Clostridium perfringens septicemia complicating degenerating uterine leiomyomas. Am J Obstet Gynecol 118: 877-878, 1974.

5. Greenspoon JS, Ault M, James BA and Kaplan L: Pyomyoma associated with polymicrobial bacteremia and fatal septic shock: Case report and review of the literature. Obstet Gynecol Surv 45: 563-569, 1990.

6. Chen JR, Yang TL, Lan FH and Lin TW: Pyomyoma mimicking advanced ovarian cancer: A rare manifestation in a postmenopausal virgin. Taiwan J Obstet Gynecol 53: 101-103, 2014

7. Manchana T, Sirisabya N, Triratanachat S, Niruthisard S and Tannirandorn Y: Pyomyoma in a perimenopausal woman with intrauterine device. Gynecol Obstet Invest 63: 170-172, 2007.

8. Kitamura Y, Ascher SM, Cooper C, Allison SJ, Jha RC, Flick PA and Spies JB: Imaging manifestations of complications associated with uterine artery embolization. Radiographics 25 (Suppl 1): S119-S132, 2005.

9. Abulafia O, Shah T, Salame G, Miller MJ, Serur E, Zinn HL, Sokolovski M and Sherer DM: Sonographic features associated with post-uterine artery embolization pyomyoma. J Ultrasound Med 29: 839-842, 2010

10. Shukla PA, Kumar A, Klyde D and Contractor S: Pyomyoma after uterine artery embolization. J Vasc Interv Radiol 23: 423-424, 2012
11. Pinto E, Trovão A, Leitão S, Pina C, Mak Fk and Lanhoso A: Conservative laparoscopic approach to a perforated pyomyoma after uterine artery embolization. J Minim Invasive Gynecol 19: 775-779, 2012.

12. Rosen ML, Anderson ML and Hawkins SM: Pyomyoma after uterine artery embolization. Obstet Gynecol 121 (2 Pt 2 Suppl 1): S431-S433, 2013

13. Weiss G, Shenker Land Gorstein F: Suppurating myoma with spontaneous drainage through abdominal wall. N Y State J Med 76: $572-573,1976$.

14. Genta PR, Dias ML, Janiszewski TA, Carvalho JP, Arai MH and Meireles LP: Streptococcus agalactiae endocarditis and giant pyomyoma stimulating ovarian cancer. South Med J 94: 508-511, 2001.

15. Fletcher H, Gibson R, Williams N, Wharfe G, Nicholson A and Soares D: A woman with diabetes presenting with pyomyoma and treated with subtotal hysterectomy: A case report. J Med Case Rep 3: 7439, 2009

16. Ono H, Kanematsu M, Kato H, Toyoki H, Hayasaki Y, Furui T, Morishige K and Hatano Y: MR imaging findings of uterine pyomyoma: Radiologic-pathologic correlation. Abdom Imaging 39: 797-801, 2014.

17. Goyal S, Mohan H, Punia RS and Tandon R: Subserosal pyomyoma and tubo-ovarian abscess in a diabetic patient. J Obstet Gynaecol 35: 101-102, 2015.

18. Lee SR, Kim BS and Moon HS: Magnetic resonance imaging and positron emission tomography of a giant multiseptated pyomyoma simulating an ovarian cancer. Fertil Steril 94: 1900-1902, 2010

19. Bedrosian L, Gabriels AG Jr and Hengerer AD: Ruptured suppurating myoma; a surgical emergency. Am J Obstet Gynecol 71: 1145-1147, 1956.

20. Fuller AF Jr and Lawrence WD: Case records of the Massachusetts General Hospital. Case 23-1985. N Engl J Med 312: 1505-1511, 1985.

21. Yang $\mathrm{CH}$ and Wang CK: Edwardsiella tarda bacteraemia-complicated by acute pancreatitis and pyomyoma. J Infect 38: 124-126, 1999.

22. Gupta B, Sehgal A, Kaur R and Malhotra S: Pyomyoma: A case report. Aust N Z J Obstet Gynecol 39: 520-521, 1999.

23. Sah SP, Rayamajhi AK and Bhadani PP: Pyomyoma in a postmenopausal woman: A case report. Southeast Asian J Trop Med Public Health 36: 979-981, 2005.

24. Yeat SK, Chong KM, Pan HS, Cheng WC, Hwang JL and Lee CC Impending sepsis due to a ruptured pyomyoma with purulent peritonitis: A case report and literature review. Taiwan J Obstet Gynecol 44: 75-79, 2005.

25. Patwardhan A and Bulmer P: Pyomyoma as a complication of uterine fibroids. J Obstet Gynaecol 27: 444-445, 2007.

26. Chen ZH, Tsai HD and Sun MJ: Pyomyoma: A rare and life-threatening complication of uterine leiomyoma. Taiwan J Obstet Gynecol 49: 351-356, 2010.

27. Kuriyama K, Makiishi T, Maeda S, Konishi T and Hirose K: Acute bilateral renal cortical necrosis complicating pyomyoma. Intern Med 49: 511-512, 2010

28. Zangeneh M, Alsadat Mahdavi A, Amini E, Davar Siadat S and Karimian L: Pyomyoma in a premenopausal woman with fever of unknown origin. Obstet Gynecol 116 (Suppl 2): S526-S528, 2010.

29. Liu HS and Chen CH: Subserosal pyomyoma in a virgin female: Sonographic and computed tomographic imaging features. Ultrasound Obstet Gynecol 37: 247-248, 2011.

30. Wong TC, Bard DS and Pearce LW: Unusual case of IUD associated postabortal sepsis complicated by an infected necrotic leiomyoma, suppurative pelvic thrombophlebitis, ovarian vein thrombosis, hematoperitoneum and drug fever. J Ark Med Soc 83: 138-147, 1986.

31. Karcaaltincaba M and Sudakoff GS: CT of a ruptured pyomyoma. AJR Am J Roentgenol 181: 1375-1377, 2003.

32. Nguyen QH and Gruenewald SM: Sonographic appearance of a postpartum pyomyoma with gas production. J Clin Ultrasound 36: 186-188, 2008

33. Stroumsa D, Ben-David E, Hiller N and Hochner-Celnikier D: Severe clostridial pyomyoma following an abortion does not always require surgical intervention. Case Rep Obstet Gynecol 2011: 364641, 2011. 